\title{
Chronic Epidural Haematoma: Case Report
}

\section{Kronik Epidural Hematom: Olgu Sunumu}

\author{
Ayhan Sarıtaş ${ }^{1}$, Ömer Aykanat ${ }^{2}$, Hayati Kandiş \\ 'Düzce Üniversitesi Tıp Fakültesi, Acil Tıp Anabilim Dalı, Düzce, Türkiye \\ ²üzce Üniversitesi Tıp Fakültesi, Beyin ve Sinir Cerrahisi Anabilim Dalı, Düzce, Türkiye
}

\section{ABSTRACT}

Chronic epidural haematomas are rarely seen in the emergency room or at outpatient clinics. They are often seen in patients under the age of 40 years. The most common symptoms are headache and hemiparaesis. Follow-up is suggested in asymptomatic cases, but surgical intervention is suggested in cases with hemiparaesis and severe headache. In this report a 87 year old woman presented with chronic epidural haematoma.

Keywords: Chronic epidural haematoma, trauma, headache Received: 09.01.2012 Accepted: 15.03.2012

\section{ÖZET}

Kronik epidural hematomlar gerek acil serviste gerek poliklinikte nadir görülürler. Kırk yaş altında daha sıktırlar. En sık rastlanan semptomlar baş ağrısı ve hemiparezidir. Klinik olarak sessiz seyreden vakalarda takip önerilirken, hemiparezi ve şiddetli baş ağrısı gibi semptomların varlığında cerrahi tedavi önerilmektedir. Bu yazıda kronik epidural hematomu olan 87 yaşında bayan bir hasta sunulmuştur.

Anahtar Kelimeler: Kronik epidural hematom, travma, baş ağrısı Geliş Tarihi: 09.01.2012 Kabul Tarihi: 15.03.2012

\section{Giriş}

Akut epidural hematomlar kafa travması sonrası oluşan ve acil serviste sık rastlanan olgulardır. Ancak kronik epidural hematomlar oldukça nadir görülmektedirler (1, 2). Büyük bir kısmı travmadan aylar ya da yıllar sonra ortaya çıkarken az bir kısmı da posterior fossa ameliyatları ya da ventriküloperitoneal şant sonrası bir komplikasyon olarak karşımıza çıkmaktadır (3). Epidural hematomlar daha çok pediatrik yaş grubunda görülmektedir. Ancak bu yaş grubunda da anatomik özelliklerinden dolayı nadiren klinik bulgu vermektedirler (4-6). Bu yazıda 87 yaşında, sağ frontal bölgesinde insidental olarak kronik epidural hematomu tespit edilen bir olguyu sunduk.

\section{Olgu Sunumu}

Seksen yedi yaşında bayan hasta solunum sıkıntısı şikayetiyle acil servise yakınları tarafından getirildi. Hastanın yapılan muayenesinde Glasgow koma skalası (GKS)15 (E4M6V5), şuuru açık, koopere ve oryanteydi. Pupiller izokorik, ışık ve kornea refleksleri bilateral pozitifti. Hastada lateralizan bulgu tespit edilmedi. Kan biyokimya ve hemogram değerlerinde belirgin patoloji tespit edilmeyen hastanın arteriyel kan gazı değerleri normal sınırlardaydı. Hastanın çekilen ön-arka akciğer grafisinde de belirgin bir patoloji tespit edilmemesi üzerine serebrovasküler bir olay olabileceği düşünülerek hastaya bilgisayarlı beyin tomografisi (BBT) çekildi. BBT'de sağ frontal bölgede en kalın yeri $9.5 \mathrm{~mm}$ olan, ventriküle bası yapmayan ve orta hat şiftine yol açmamış kronik epidural hematomla uyumlu görünüm izlendi (Resim 1a). Kemik pencerede ise belirgin bir patoloji tespit edilmedi (Resim 1b). Beyin ve sinir cerrahisi tarafından konsülte edilen hastaya takip amacıyla yatış önerildi. Ancak beyin ve sinir cerrahisinin yatış önerisini kabul etmeyen hasta kendi isteği ile taburcu edildi.

\section{Tartışma}

Kronik epidural hematomlar nadir görülen ve nadiren semptom veren kanamalardır. Semptomlar arasında en sık olarak hemiparezi ve baş ağrısına rastlanılmaktadır (7). Kronik epidural hematomların etyolojisinde çoğunlukla travma yer almaktadır ve direkt radyografilerde ya da BBT'de genellikle kırık hattı görülmektedir. Ancak olguların yaklaşık \%15'inde kırık bulunmamaktadır. Özellikle çocuk hastalarda kırık hattına daha nadir rastlanılmaktadır (8). Travma dışında koagülasyon bozukluğu da bir 

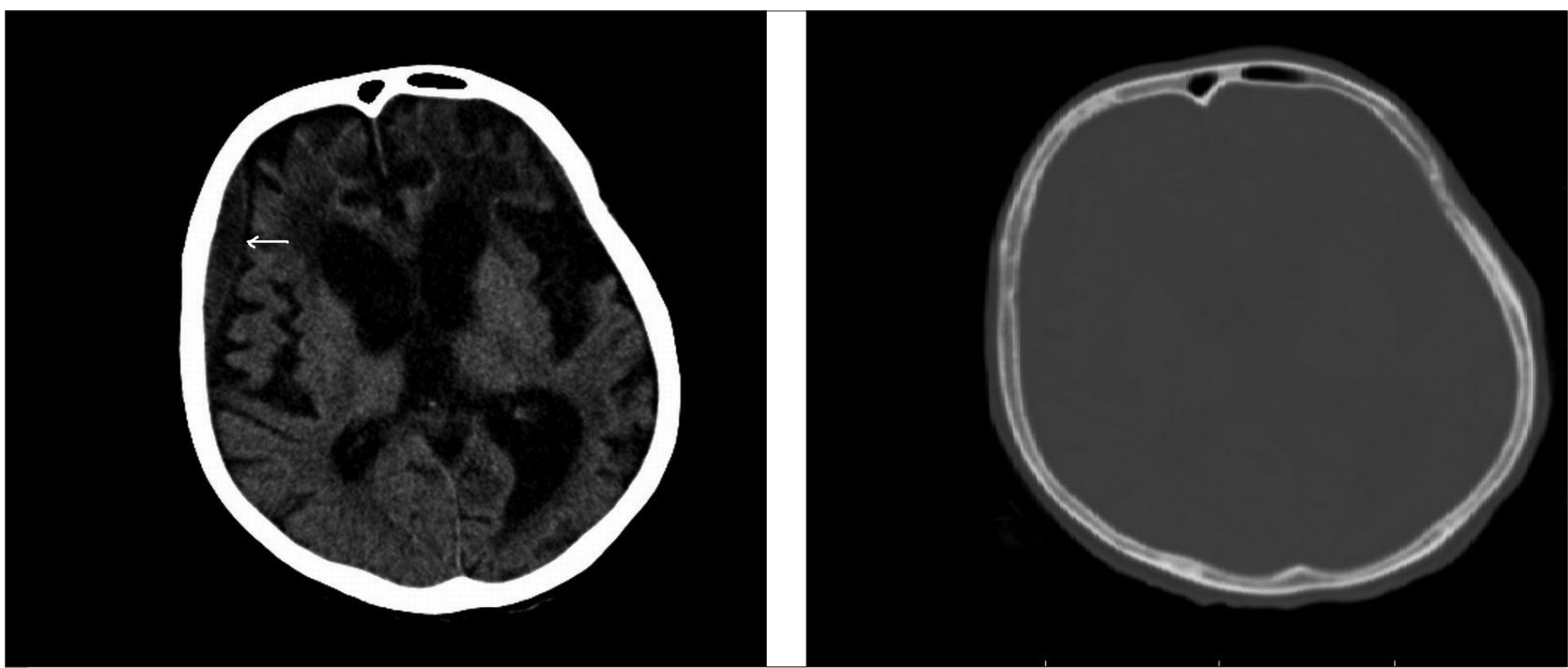

Resim 1a. Aksiyel kesitli kranial BBT incelemesinde sağ frontal bölgede en kalın yeri 9.5 mm olan, ventriküle bası yapmayan ve orta hat şiftine yol açmamış kronik epidural hematomla uyumlu görünüm izlenmektedir. b. Aynı hastanın aksiyel kesitli kranial BBT kemik parankim incelemesinde belirgin bir patoloji izlenmemektedir.

diğer etyolojik faktördür. Kronik epidural hematomlara sıklıkla 40 yaş altında rastlanımaktadır. Bunun sebebi olarak da yaşılarda duranın kafatasına sıkıca yapışık olması gösterilmektedir $(4,5,7)$. Olgumuzda hastanın 87 yaşında olması ve BBT'de kırık hattının görülmemesi literatürle farklılık arzetmektedir. Kronik epidural hematomların nadiren ve geç semptom vermesinin sebebi olarak kanamanın venöz orjinli olması ve hematomun yerleşim yerinin atipik olması gösterilmektedir. Akut epidural hematomların sıklıkla temporal bölge yerleşimli olmasına rağmen kronik epidural hematomlarda vakaların \%50'sinde hematomun yerleşim yeri temporal bölge dışında başka bir bölgedir. Young'ın (9) yaptığı bir derlemede vakaların yaklaşık yarısında epidural hematomun atipik yerleşimli olması bu durumu desteklemektedir. Beyin temporal bölge ya da posterior fossa yerleşimli bir hematomu tolere edemeyip bulgu verirken, frontal ya da parietal yerleşimli bir hematomu kolayca tolere edebilmektedir. Bundan dolayı da atipik yerleşimli hematomların kronikleşmesine daha sık rastlanılmaktadır $(7,10)$.

Kronik epidural hematomların tedavisi duruma göre ya cerrahi ya da klinik takiptir. Beyinde orta hat şiftine yol açmayan ve semptom vermeyen küçük vakalar takip edilebilirken bulgu veren büyük hematomların boşaltılması gerekmektedir. Takip edilen vakaların bir kısmı spontan olarak rezorbe olup kaybolmakta diğer kısmı ise kalsifiye olmaktadır $(2,10)$.

\section{Sonuç}

Acil serviste nadir görülen kronik epidural hematomlu bir olguyla karşılaşıldığında hasta, beyin ve sinir cerrahisi bölümü ile hızlı bir şekilde konsülte edilerek hastanın gerekli medikal ve ya cerrahi tedavisi planlanmalıdır.

\section{Çıkar Çatışması}

Yazarlar herhangi bir çıkar çatışması bildirmemişlerdir.

\section{Kaynaklar}

1. Bonilha L, Mattos JP, Borges WA, Fernandes YB, Andrioli MS, Borges G. Chronic epidural hematoma of the vertex. Clin Neurol Neurosurg 2003; 106: 69-73. [Crossref]

2. Kotil K, Akçetin MA. Asymptomatic chronic ossified epidural hematoma in a child: A rare entity. Ulus Travma Acil Cerrahi Derg 2006; 12: 164-6.

3. Bayri Y, Ulas AK, Ulus A, Kaya AH, Dagcınar A. latrogenic Chronic Calcified/Ossified Epidural Hematoma: Case report. J Nervous Sys Surgery 2009; 2: 91-4

4. Iwakuma T, Brunngraber CV. Chronic extradural haematomas: A study of 21 cases. J Neurosurg 1973; 38: 488-93. [Crossref]

5. Tatagiba M, Sepehrnia A, El Azm M, Samii M. Chronic epidural hematoma: Report on eight cases and review of the literature. Surg Neurol 1989; 32: 453-8. [Crossref]

6. Miller DJ, Steinmetz M, McCutcheon IE. Vertex epidural hematoma: Surgical versus conservative management: two case reports and review of the literature. Neurosurgery 1999; 45: 621-5. [Crossref]

7. Topuz K, Güven G, Kutlay M, Çolak A, Demircan MN, Çetinkal A. Bulgu vermemiş kronik temporal epidural hematom: Olgu Sunumu. Türk Nöroşirürji Dergisi 2011; 21: 53-5.

8. Soloniuk D, Pitts LH, Lovely M, Bartkowski H. Traumatic intracerebral hematomas: Timing of appearance and indications for operative removal. J Trauma 1986; 26: 787-94. [Crossref]

9. Young TW. Chronic extradural haematoma. Brit JClin Pract 1972; 26: 38-41.

10. Nagane M, Oyama H, Shibui S, Nomura K, Nakanishi Y, Kamiya M. Ossified and calcified epidural hematoma incidentally found 40 years after head injury: Case report. Surg Neurol 1994; 42: 65-9. [Crossref] 